\title{
Güneydoğu Anadolu Bölgesi’nde Kamu Tarım Yatırımlarının Dağılımının Gini Katsayısı ile Ölçülmesi*
}

\author{
Şekip YAZGAN ${ }^{1 * *(D)} \quad$ Esra KADANALI ${ }^{2}$ (i) \\ ${ }^{1}$ Ağrı İbrahim Çeçen Üniversitesi, İktisadi ve İdari Bilimler Fakültesi, İktisat Bölümü, Ağrı, Türkiye \\ ${ }^{2}$ Ağrı İbrahim Çeçen Üniversitesi, İktisadi ve İdari Bilimler Fakültesi, İşletme Bölümü, Ağrı, Türkiye \\ (**Sorumlu yazar e-mail: syazgan@agri.edu.tr)
}

DOI: 10.17097/ataunizfd.502873

Geliş Tarihi (Received Date): 26.12.2018

Kabul Tarihi (Accepted Date): 09.04.2019

\begin{abstract}
ÖZ: Çalışmada, Türkiye'de uygulanan en kapsamlı bölgesel kalkınma projesi olan Güneydoğu Anadolu Projesi (GAP) illerini içeren Güneydoğu Anadolu (TRC) Bölgesine yapılan kamu tarım yatırımlarının 2000-2017 yılları arasında hangi ölçüde eşit/eşitsiz dağıldı̆̆ı Gini Katsayısı ile ortaya konulmaktadır. Elde edilen ampirik bulgular inceleme döneminde kamu tarım yatıımları için hesaplanan Gini Katsayısının ortalama değerinin 0.712 seviyesinde bulunduğunu ve kamu tarım yatırımlarının TRC Bölgesinde eşitsiz dağıldığını göstermektedir. TRC Bölgesinde bölge içi ve bölgeler arası eşitsizliğin toplam eşitsizliğe katkısının ortaya çıkarılması amacıyla yapılan Gini Katsayısı Ayrıștırma Analizi sonuçları ise 2000 y1lından 2017 yılına gelindiğinde TRC Bölgesinde bölgeler arası eşitsizliğin azalmaya başladığını ancak bölge içi eşitsizliğin arttığını göstermektedir.
\end{abstract}

Anahtar Kelimeler: Kamu tarım yatırımları, Bölgesel kalkınma, Gini Katsayısı, Güneydoğu Anadolu Bölgesi

Measurement of Public Agricultural Investments Distribution in Southeastern Anatolia Region with Gini Coefficient

\begin{abstract}
The study reveals the equal/unequal distribution of the public agricultural investments that have been implemented in the region of Southeastern Anatolia Region (TRC) with the Gini coefficient. The region includes the districts of Southeastern Anatolia Project (GAP), as the most comprehensive regional development project in Turkey. The empirical findings reveal that the average value of the Gini Coefficient for public agricultural investments is 0.712 . Therefore, public agricultural investments are unevenly distributed in the TRC region. The results of the Gini Coefficient Decomposition Analysis conducted in order to explain the inequality of intra-regional and inter-regional inequality in the TRC Region show that the inequality between regions has started to decrease in the TRC Region from 2000 to 2017, while the inequality within the region has increased.
\end{abstract}

Keywords: Public agricultural investments, Regional development, Gini coefficient, Southeastern Anatolia Region

\section{GÍRIS}

Kamunun ekonomiye müdahale edip etmeyeceği ve edecekse bu müdahalenin hangi alanlara ve ne şekilde yapılması gerektiği konusu iktisat yazınında sürekli olarak tartışılagelen konular arasında yer almaktadır. Kamunun ekonomiye müdahale araçlarından en önemlisi olan kamu harcamalarının büyük kısmını ise kamu yatırımları oluşturmaktadır. İçsel Büyüme Teorilerinde, kamu yatırımlarının, ekonominin üretim kapasitesini ve insan sermayesinin gelişimini arttırma gibi önemli etkilerinin bulunduğu ve devletin özellikle eğitim, sağlık, teknoloji ve altyapı yatırımları ile ekonomik büyümeye ivme kazandırabildiği ifade edilmektedir (Lucas, 1988; Romer, 1990; Barro, 1990). Bunun yanında kamu yatırımları, ülke içerisindeki bölgeler arasında gelişmişlik farklarının giderilmesinde kullanılan önemli bir araç durumunda bulunmaktadır. $\mathrm{Bu}$ bağlamda kamu yatırımlarının bölgesel düzeydeki dağılımı, bölge ekonomilerini etkilediği gibi, bu bölgelerin ulusal gelirden aldıkları payları da etkilemektedir. Bir ülke içerisinde kamu yatırımlarının daha dengeli dağıtılması, bölgesel gelirlerin de daha dengeli dağılmasını sağlamaktadır. Bölgesel eşitsizlik olarak tanımlanabilecek bölgeler arasındaki gelişmişlik farkları, çeşitli alanlardaki kamu yatırımlarından doğrudan ve dolaylı olarak etkilenmektedir (Dinler, 2014; Öztürk, 2012).

$\mathrm{Bu}$ çalışmada, sulama, bitkisel üretim, hayvancıllk, su ürünleri, ormanc1lı sektörlerine yapılan proje yatırımları olarak ifade edilen kamu tarım yatırımlarının Güneydoğu Anadolu (TRC) Bölgesinde iller ve alt bölgeler bazında ne kadar eşit/eşitsiz dağıldığı 2000-2017 dönemi için yıllık bazda ve Gini Katsayısı kullanılarak incelenmektedir. Bu kapsamda çalışmanın ilk aşamasında, bünyesinde Gaziantep, Adıyaman, Kilis, Şanlıurfa, Diyarbakır, Mardin, Batman, Şırnak ve Siirt illeri bulunan TRC Bölgesinde kamu tarım yatırımlarının dağılımını ölçmek için Gini Katsayısı değerleri hesaplanmaktadır. TRC Bölgesi, Türkiye'deki 12 Düzey-1 bölgesinden birisi olmasının yanı sıra Türkiye'nin önemli bölgesel kalkınma projelerinden birisi olan Güneydoğu Anadolu Projesi (GAP) illerini de bünyesinde barındırmaktadır. $\mathrm{Bu}$ çerçevede çalışmanın ikinci aşamasında, TRC Bölgesi dolayısıyla GAP Projesi illeri için hesaplanan kamu tarım yatırımları Gini Katsayısı değerleri, Kuzeydoğu Anadolu Bölgesi (TRA), Ortadoğu Anadolu Bölgesi (TRB) ve söz konusu Düzey-1 Bölgesi illerinin çok büyük bir bölümünü içeren Doğu Anadolu Projesi 
(DAP) illeri için de hesaplanarak karşılaştırma yapılmaktadır. Çalışmada son olarak, TRC Bölgesinde kamu tarım yatırımları Gini Katsayısı değeri ile ifade edilen eşitsizliğin ne kadarının kamu tarım yatırımlarının TRC Bölgesinde bulunan iller ve alt bölgelerin içindeki dağılımından, ne kadarının ise bölgeler arasındaki dağılım farklılığından kaynaklandığının ortaya konulması amacıyla Gini Katsayısı Ayrıştırma Analizi yapılmaktadır. Çalışma, değerlendirmelerin yapıldığı sonuç bölümüyle tamamlanmaktadır.

\section{MATERYAL VE METOT}

\section{Materyal}

Çalışmada ikincil veriler kullanılmakta ve inceleme dönemi olan 2000-2017 yılları arasında yapılan kamu tarım yatırım (sulama, bitkisel üretim, hayvancılık, su ürünleri, ormanc1lık sektörlerine yapılan proje yatırımları) miktarları Kalkınma Bakanlığg verilerinden derlenmektedir.

\section{Metot}

Çalışmada TRC Bölgesine yapılan kamu tarım yatırımlarının ne kadar eşit/eşitsiz dağıldığını belirlemek için hesaplanan ve İtalyan istatistikçi Gini (1912) tarafından geliştirilen Gini Katsayısı, basitliği ve dağılımı tek bir katsayı ile göstermesi nedeniyle iktisat literatüründe yaygın bir biçimde gelir dağılımı

$G=\frac{2}{\bar{y}} \operatorname{Cov}(y, F(y))$

Yukarıda 1 numaralı denklemde Cov (y, F(y)), illerin birikimli dağılımı ile kamu tarım yatırımlarının kovaryansını, $\bar{y}$ ise illere yapılan kamu tarım yatırımlarının ortalamasını göstermektedir.

Gini Katsayısı ayrıca bir eşitsizlik ölçüsü olarak, bütünü oluşturan parçalara ayrıştırılabilmekte ve bu sayede eşitsizliğin kaynağ1 belirlenebilmektedir. Tarihsel olarak bakıldığında, Gini Katsayısının, gelir kaynağına göre ayrıştırma ve gruplar arası ayrıştırma olarak iki alana odaklandığı görülmektedir (Ceriani and Verme, 2014; Kaya ve Şenesen, 2011). TRC Bölgesi, TRC1, TRC2 ve TRC3 olmak üzere üç adet Düzey-2 Bölgeden oluşmaktadır. Gaziantep, Adıyaman ve Kilis illeri

$G=G_{B}+\sum a_{k} G_{k}+\mathrm{R}$

Denklem 2'de G, TRC Bölgesi için hesaplanan Gini Katsayısı değerini göstermektedir. $G_{k}$, ise alt bölgeler TRC1, TRC2 ve TRC3 Bölgeleri için hesaplanan Gini Katsayısı değerini belirtmektedir. Alt bölgeler için hesaplanan Gini Katsayısı değerlerinin sirasıyla TRC1, TRC2 ve TRC3 Bölgelerinin nüfus ve kamu tarım yatırım oranlarıyla eşitsizliğini belirlemek ve çeşitli gelir dağılımlarını karşılaştırılmak için kullanılmaktadır (Şenses, 2017). Eşitsizliğin ölçülmesinde kullanışlı bir araç olan Gini Katsayısının literatürde başta sağlık alanı (Brown, 1994; Lee, 1996, 1997) olmak üzere farklı disiplinler tarafından da kullanıldığı (Örneğin, su kullanımında Cullis and Van Koppen (2007), yaşam süresi dağılımında Geyik vd. (2005), tarım sübvansiyonlarının dağılımında Samman (2005), eğitim konusunda Tomul (2011), sayısal bölünme düzeyinde Fidan (2017) ve ulaşımda güvenirlik analizinde Lee et al. (2017) görülmektedir.

Gini Katsayısı, grafiksel yaklaşım (Lorenz Eğrisi), göreli ortalama farkı yaklaşımı, kovaryans yaklaşımı ve matris formu yaklaşımı olmak üzere dört farklı yaklaşımla hesaplanabilmektedir (Xu, 2003). Gini Katsayısı 0 ve 1 arasında bir değer almaktadır. Gini Katsayısının 0 değerini alması mutlak eşitlik, 1 değerini alması ise mutlak eşitsizlik anlamına gelmektedir. Dolayısıyla katsayının zaman içerisinde küçülmesi (artması) eşitsizliğinin azalmasına (artmasına) işaret etmektedir (Şenses, 2017).

Çalışmada Gini Katsayısının hesaplanmasında kovaryans yaklaşımı kullanılmaktadır. Kovaryans yaklaşımına göre Gini Katsayısı aşağıda 1 numaralı denklemde gösterildiği şekilde hesaplanmaktadır (Lerman and Yitzhaki, 1985).

TRC1, Şanlıurfa ve Diyarbakır illeri TRC2, Mardin, Batman, Şırnak ve Siirt illeri ise TRC3 Bölgesinde bulunmaktadır. Çalışmada TRC Bölgesi için hesaplanan Gini Katsayısı değeri, bölgenin alt bölgeleri olan TRC1, TRC2 ve TRC3 Bölgeleri arasında ayrıştırılmakta ve eşitsizliğin ne kadarının bölgelerin içindeki dağılımdan ne kadarının ise bölgeler arası kamu tarım yatırımlarının dağılımındaki farklılıklardan kaynaklandığı belirlenmektedir. Gini Katsayısının ayrıştırılması için Lambert and Aronson (1993) tarafindan geliştirilen yöntem kullanılmaktadır. Gini ayrıştırması için kullanılan formül aşağıda 2 numaralı denklemde ifade edilmektedir (Lambert and Aronson,1993):

ağırlıklandırılması sonucunda elde edilen değer grup (bölge) içi ayrıştırma değerini vermektedir. Gruplar (bölgeler) arası ayrıştırma değeri olan $G_{B}$, TRC1, TRC2 ve TRC3 Bölgelerinin ortalama kamu tarım yatırımları dağılımları kullanılarak hesaplanmaktadır. Denklemde 2'de bulunan $\mathrm{R}$, ise artık veya örtüşme olarak tanımlanmaktadır. Eğer TRC1, TRC2 ve 
TRC3 alt bölgelerine yapılan kamu tarım yatırımları çakışmazsa örtüşme değeri 0 değerini almaktadır (Lambert and Aronson, 1993; Easypol, 2006). Örtüşme değerinin 0 olduğu durumda grup (bölge) içi ve gruplar (bölgeler) arası ayrışma değerlerinin toplamı TRC Bölgesi için hesaplanan Gini Katsayısını vermektedir.

İlgili literatür incelendiğinde kamu yatırımlarının dağılımındaki eşitsizliği Gini Katsayısı kullanarak inceleyen oldukça sınırlı sayıda çalışma bulunduğu görülmektedir. Öztürk (2012) çalışmasında, Türkiye'de kamu yatırımları ile bölgesel eşitsizlik arasındaki ilişki 1975-2001 dönemi için incelenmektedir. Çalışmada hem kamu yatırımlarının hem de Gayri Safi Yurtiçi Hasıla (GSYIH)'nın iller arasında hangi ölçüde eşitsiz dağıldığı Gini katsayısı yardımıyla hesaplanmaktadır. Çalışmada iller arasındaki gelir eşitsizliğinin 1980'lere doğru düzenli bir artış gösterdiği ancak 1990 'lı yıllarda nispeten azaldığı, 1975 yılında 0.470 olan Gini Katsayısı değeriyle ifade edilen kamu yatırımlarındaki eşitsizliğin ise özellikle 1990'lı yılların sonlarına doğru arttı̆̆ ve 2001 ekonomik krizinde 0.652 değerini alarak en yüksek düzeyine eriştiği ifade edilmektedir. Ayrıca çalışmada, Türkiye'de kamu yatırımlarının bölgesel eşitsizliklerin giderilmesinde önemli bir faktör olduğu belirtilmektedir. Yazgan (2018) çalışmasında ise, 1999-2017 yılları arasında tarım, madencilik, imalat, enerji, ulaştırma-haberleşme, turizm, konut, eğitim, sağlık sektörlerine ve diğer kamu hizmetlerine yapılan kamu yatırımları ve toplam kamu yatırımlarının iller arasında dağılımı Gini Katsayisı kullanarak incelenmektedir. Yazgan (2018) çalışmasında elde edilen ampirik bulgular, imalat sanayi kamu yatırımları hariç tüm kamu yatırımları için hesaplanan Gini Katsayısı değerlerinin dönem içerisinde azaldığını ve kamu yatırımlarının iller arasında nispeten daha eşit dağıldığını ortaya koymaktadır. Söz konusu çalışmada ayrıca Lerman and Yitzhaki (1985) tarafindan geliştirilen Gini Katsayısı Ayrıştırma Tekniği kullanılarak hangi kamu yatırımının toplam kamu yatırımı için hesaplanan eşitsizlik üzerinde daha etkili olduğu belirlenmektedir. Çalışmada toplam kamu yatırımları için hesaplanan ve Gini Katsayısıyla ifade edilen eşitsizliğin büyük bölümü 1999 yllında diğer kamu hizmetleri, enerji ve ulaştırma-haberleşme sektörlerine yapılan kamu yatırımlarının dağılımından, 2017 yılında ise diğer kamu hizmetleri, ulaştırma-haberleşme ve eğitim sektörlerine yapılan kamu yatırımların dağılımdan kaynaklandığ sonucuna ulaşılmaktadır.

Öztürk ve Aktar (2009) ve Yazgan ve Kadanalı (2018) ise çalışmalarında sırasıyla Karadeniz ve TRA Bölgelerinde kamu tarım yatırımlarının dağıllımını Gini Katsayısı kullanarak incelemektedirler. Öztürk ve Aktar (2009) çalışmalarında, 2000-2007 döneminde Karadeniz Bölgesinde bulunan illerde kamu tarım yatırımları için elde edilen Gini Katsayısı ortalama değeri 0.64 gibi yüksek bir seviyede bulunduğunu ve bu değerin inceleme döneminde Karadeniz Bölgesinde kamu tarım yatırımlarının eşit dağılmadığını sonucuna ulaşmaktadırlar. 1999-2017 yılları arasında TRA Bölgesi illeri ve alt bölgelerinde kamu tarım yatırımlarının dağılımını inceleyen Yazgan ve Kadanalı (2018) ise çalışmalarında, TRA Bölgesi ve alt bölgeleri olan, bünyesinde Erzurum, Erzincan, Bayburt illeri bulunan TRA1 Bölgesi ve Ağrı, Kars, Iğdır ve Ardahan illerini içeren TRA2 Bölgesine ait kamu tarım yatırımları Gini Katsayısı değerlerinin söz konusu dönemin başlarında nispeten düşük seviyelerde bulunduğunu yani kamu tarım yatırımlarının iller arasında nispeten eşit bir biçimde dağıldığını ancak dönem boyunca katsayı değerlerinin yükselerek eşitsizliğin arttığı ifade etmektedirler. Söz konusu çalışmada, inceleme döneminde TRA, TRA1 ve TRA2 Bölgeleri için ortalama Gini Katsayısı değerleri sırasıyla 0.410, 0.433 ve 0.262 olarak hesaplanmaktadır. Bu durum üç bölge içerisinde kamu tarım yatırımlarının nispi olarak en eşit dağıldığ eşitsiz dağılan bölgenin ise TRA1 Bölgesi olduğunu göstermektedir. Çalışmada yapılan Gini Katsayısı Ayrıştırma Analizi sonuçları ise inceleme döneminde, bölgeler arası eşitsizliğin toplam eşitsizliğe katkısının azaldığını, bölge içi eşitsizliğin ve örtüşmenin ise arttığını göstermektedir.

Çalışmada TRC Bölgesine yapılan kamu tarım yatırımlarının dağılımı incelenerek literatürde sınırlı sayıda bulunan çalışmalara katkı sağlanması amaçlanmaktadır.

\section{BULGULAR VE TARTISSMA}

Cumhuriyet tarihinin en kapsamlı ve maliyetli projesi olmasının yanında Türkiye'de bugüne kadar hazırlanan bölgesel kalkınma plan ve programları arasında en etkin olarak uygulanan projesi olan Güneydoğu Anadolu Projesi (GAP) illerini içeren TRC Bölgesi, nüfus açısından ülkemizin yüzde 10'luk bölümüne tekabül etmektedir. Bölgenin yaklaşık yüzde 42,6'lık kısmı tarımsal faaliyetler için elverişlidir ve tarım sektörü bölgenin en önde gelen sektörü durumunda bulunmaktadır. Türkiye'nin ekonomik olarak sulanabilir arazisinin yüzde 20 'si TRC Bölgesinde bulunmaktadır. GAP Projesi ile hidroelektrik santralleri ve sulama projelerinin yanı sıra, tarım, sanayi, enerji, ulaştırma, eğitim, sağlık, kırsal ve kentsel altyapı yatırımları ile bölgenin ekonomik ve sosyal göstergelerinin arttırılarak ülke ortalamas1 seviyesine getirilmesi hedeflenmektedir (Anonim, 2018a).

İnceleme dönemi olan 2000-2017 yılları arasındaki dönemde seçili yıllarda TRC Bölgesi illeri 
ve Alt Bölgelerinin kamu tarım yatırımlarından aldıkları paylar aşağıda Çizelge 1'de gösterilmektedir. Çizelge 1 incelendiğinde TRC Bölgesinde, il bazında Şanlıurfa ve Diyarbakır'ın kamu tarım yatırımlarından en fazla payları aldıkları görülmektedir. 2000-2017 yılları arasında Şanlıurfa kamu tarım yatırımlarının ortalama yüzde 47,7'sini, Diyarbakır ise yüzde 33,8'ini almaktadır. En fazla kamu tarım yatırımı yapılan bu iki ili yüzde 9,3 ile Gaziantep, yüzde 5,6 ile Adıyaman, yüzde 1 ile Mardin illeri takip etmektedir. TRC Bölgesinde kamu tarım yatırımlarından en az payı alan iller ise ortalama yüzde 0,9 ile Kilis, yüzde 0,71 ile Batman, yüzde 0,59 ile Şırnak ve yüzde 0,19 ile Siirt ili olarak sıralanmaktadır. TRC Bölgesini oluşturan Düzey-2 alt bölgelerinde kamu tarım yatırımlarının dağılımına bakıldığında ise, Şanlıurfa ve Diyarbakır illerinin bulunduğu TRC2 Bölgesinin yüzde 81,57'lik ortalama pay ile en fazla kamu tarım yatırımı yapılan alt bölge olduğu görülmektedir. TRC2 Bölgesini ortalama yüzde 15,90 'luk pay ile TRC1 Bölgesi ve yüzde 2,54'lük pay ile TRC3 Bölgesi takip etmektedir.

Çizelge 1.TRC Bölgesi İllerine / Alt Bölgelerine Yapılan Kamu Tarım Yatırımları (\%)

\begin{tabular}{lccccc}
\hline İler / Alt Bölgeler & $\mathbf{2 0 0 0}$ & $\mathbf{2 0 0 6}$ & $\mathbf{2 0 1 2}$ & $\mathbf{2 0 1 7}$ & $\mathbf{2 0 0 0 - 2 0 1 7}$ \\
\hline Gaziantep & 14,32 & 16,39 & 11,28 & 5,86 & 9,33 \\
Adıyaman & 7,03 & 11,85 & 2,95 & 7,98 & 5,60 \\
Kilis & 0,64 & 1,00 & 1,65 & 2,31 & 0,97 \\
\hline TRC1 Bölgesi & 21,99 & 29,24 & 15,88 & 16,16 & 15,90 \\
\hline Şanlıurfa & 53,86 & 47,62 & 41,55 & 10,95 & 47,73 \\
Diyarbakır & 23,57 & 22,70 & 38,24 & 69,88 & 33,84 \\
\hline TRC2 Bölgesi & 77,43 & 70,32 & 79,79 & 80,83 & 81,57 \\
\hline Mardin & 0,00 & 0,19 & 2,44 & 0,89 & 1,04 \\
Batman & 0,01 & 0,12 & 1,34 & 1,10 & 0,71 \\
Şırnak & 0,57 & 0,05 & 0,53 & 0,72 & 0,59 \\
Siirt & 0,00 & 0,08 & 0,02 & 0,30 & 0,19 \\
\hline TRC3 Bölgesi & 0,58 & 0,44 & 4,33 & 3,01 & 2,54 \\
\hline
\end{tabular}

Kaynak: Anonim, 2018b.

Kamu tarım yatırımlarının 2000-2017 yılları arasındaki dönemde TRC Bölgesi illeri arasında eşit dağılıp dağılmadığını analiz etmek için hesaplanan Gini Katsayısı değerleri aşağıda Çizelge 2'de sunulmaktadır. Çizelge 2'de görüldüğü üzere TRC Bölgesinde 2000 yılında 0.714 olan kamu tarım yatırımları Gini Katsayısı değeri yüzde 2,10 oranında artarak 2017 yılında 0.729 seviyesine ulaşmaktadır. İnceleme döneminde TRC Bölgesinde kamu tarım yatırımları için hesaplanan Gini Katsayısı değerlerinin ortalaması ise 0.712 'dir. Elde edilen bu yüksek Gini Katsayısı değerleri TRC Bölgesinde kamu tarım yatırımlarının eşit dağılmadığını göstermektedir.

Çizelge 2. TRC Bölgesi için Yıllar İtibariyle Hesaplanan Gini Katsayıları Değerleri

\begin{tabular}{cccc}
\hline Yıllar & Gini Katsayısı Değeri & Yıllar & Gini Katsayısı Değeri \\
\hline 2000 & 0.714 & 2009 & 0.713 \\
2001 & 0.699 & 2010 & 0.732 \\
2002 & 0.733 & 2011 & 0.716 \\
2003 & 0.838 & 2012 & 0.668 \\
2004 & 0.823 & 2013 & 0.674 \\
2005 & 0.820 & 2014 & 0.684 \\
2006 & 0.672 & 2015 & 0.711 \\
2007 & 0.605 & 2016 & 0.677 \\
2008 & 0.606 & 2017 & 0.729 \\
\hline & & Ortalama Dĕger & $\mathbf{0 . 7 1 2}$
\end{tabular}

İnceleme döneminde TRC Bölgesi Kamu Tarım Yatırımları Gini Katsayısı Değerlerinin seyri ise aşağıda Şekil 1'de gösterilmektedir. Çizelge 2 ve Şekil 1 birlikte incelendiğinde 2000-2017 yılları arasındaki dönemde Gini Katsayısının 0.605 ve 0.838 arasında değerler aldığı görülmektedir. Gini Katsayısı 2003 yılında 0.838 değerini alarak en yüksek seviyeye ulaşmaktadır. Gini Katsayısı değerinin en az olduğu yıl ise 0.605 değeriyle 2007 yılıdır. Hesaplanan bu Gini Katsayısı değerleri kamu tarım yatırımlarının en eşitsiz dağıldığı yılın 2003 yılı, en eşit dağıldı̆̆ yılın ise 2007 yılı olduğunu göstermektedir. 


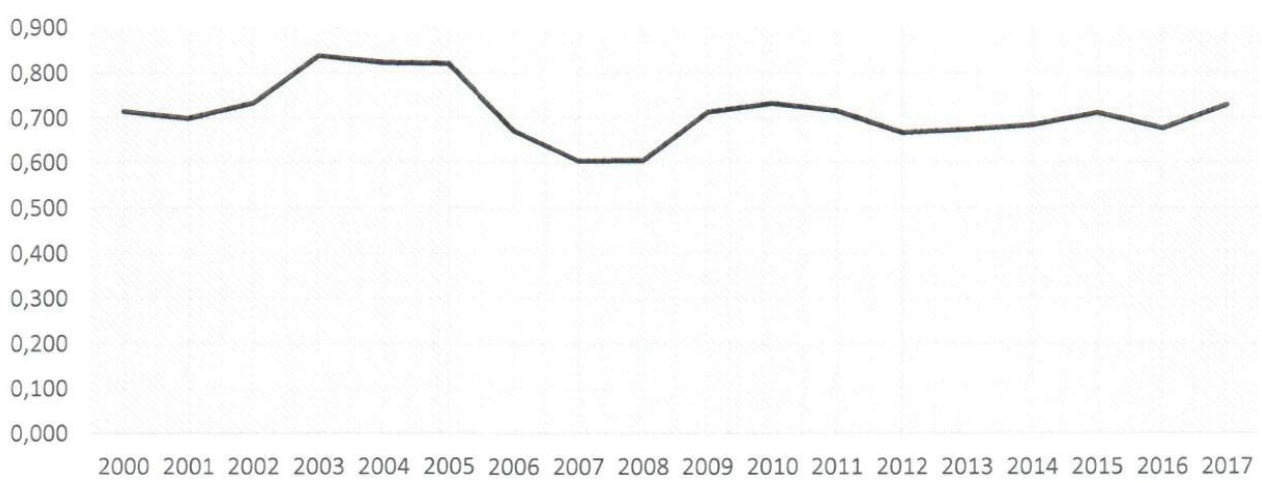

—TRC Bölgesi Gini Katsayısı Değerleri

Şekil. 1. TRC Bölgesi Kamu Tarım Yatırımları Gini Katsayısı Değerlerinin Seyri (2000-2017)

Çalışmada, karşılaştırma yapmak amacıyla, bölge ekonomisi içerisinde tarım faaliyetlerin önem arz ettiği ve Türkiye'nin doğusunda bulunan diğer Düzey-1 bölgeleri olan TRA (Erzurum, Erzincan, Bayburt, Ağrı, Kars, Iğdır, Ardahan) ve TRB (Malatya, Elâzı̆̆ Bingöl, Tunceli, Van, Muş, Bitlis, Hakkâri) Bölgeleri ve TRA Bölgesinde bulunan Bayburt ili hariç TRA ve TRB Bölgesi bünyesinde bulunan illerden ve Sivas ilinden oluşan DAP Bölgesi için de kamu tarım yatırımları için Gini Katsayısı hesaplanmaktadır. Bu yolla TRC Bölgesi ve dolayısıyla GAP İllerinde gerçekleşen kamu tarım yatırımlarının dağılımının TRA, TRB ve DAP ile karşılaştırılması amaçlanmaktadır. Aşağıda Çizelge 3'te 2000-2017 döneminde TRA, TRB ve DAP
Bölgesi illeri için hesaplanan Gini Katsayısı değerleri ve inceleme dönemindeki ortalama Gini Katsayısı değerleri gösterilmektedir.

Çizelge 3 incelendiğinde, 2000-2017 dönemi itibariyle TRA ve TRB Bölgeleri kamu tarım yatırımları dağılımı için hesaplanan Gini Katsayısı ortalama değerlerinin sirasıyla 0.422 ve 0.467 seviyesinde bulunduğu görülmektedir. Bu değerler, ortalama Gini Katsayısı değerinin 0.712 olduğu TRC Bölgesiyle karşılaştırıldığında söz konusu üç bölge içerisinde kamu tarım yatırımlarının en eşitsiz dağılldı̆̆ bölgenin TRC Bölgesi, nispeten en eşit dağılldığ bölgenin ise TRA Bölgesi olduğunu göstermektedir.

Çizelge 3. TRA, TRB ve DAP Bölgeleri için Yıllar İtibariyle Hesaplanan Gini Katsayıları Değerleri

\begin{tabular}{cccc}
\hline Yllar & $\begin{array}{c}\text { TRA Bölgesi } \\
\text { Gini K.D. }\end{array}$ & $\begin{array}{c}\text { TRB } \\
\text { Bölgesi Gini K.D. }\end{array}$ & $\begin{array}{c}\text { DAP } \\
\text { Bölgesi Gini K.D. }\end{array}$ \\
\hline 2000 & 0.316 & 0.480 & 0.399 \\
2001 & 0.298 & 0.465 & 0.371 \\
2002 & 0.349 & 0.460 & 0.384 \\
2003 & 0.541 & 0.611 & 0.555 \\
2004 & 0.540 & 0.578 & 0.523 \\
2005 & 0.507 & 0.478 & 0.455 \\
2006 & 0.476 & 0.429 & 0.407 \\
2007 & 0.445 & 0.465 & 0.439 \\
2008 & 0.406 & 0.480 & 0.430 \\
2009 & 0.414 & 0.622 & 0.512 \\
2010 & 0.418 & 0.568 & 0.498 \\
2011 & 0.467 & 0.536 & 0.481 \\
2012 & 0.495 & 0.443 & 0.463 \\
2013 & 0.409 & 0.343 & 0.432 \\
2014 & 0.342 & 0.326 & 0.400 \\
2015 & 0.362 & 0.350 & 0.365 \\
2016 & 0.382 & 0.386 & 0.407 \\
2017 & 0.423 & 0.387 & 0.434 \\
\hline
\end{tabular}


Gini Katsayısının ortalama değerleri yanında 2000-2017 döneminin tamaminda da TRC Bölgesi kamu tarım yatırımları Gini Katsayısı değerlerinin TRA ve TRB Bölgelerine ait Gini Katsayıs1 değerlerinden daha yüksek seviyede bulunduğu Şekil 2'de görülmektedir. Bu durum inceleme döneminde TRC Bölgesinde kamu tarım yatırımlarının TRA ve TRB Bölgelerine kıyasla daha eşitsiz dağıldı ̆̆ını göstermektedir. TRA ve TRB Bölgeleri arasında bir karşılaştırma yapıldığında ise 2005-2006, 2012-2015 ve 2017 yıllarında TRA Bölgesinin TRB Bölgesine kıyasla daha yüksek Gini Katsayısı değerlerine sahip olduğu görülmektedir. Bu durum söz konusu bu yıllarda TRA Bölgesindeki kamu tarım yatırımlarının TRB Bölgesine göre daha eşitsiz dağıldığı şeklinde yorumlanmaktadır.

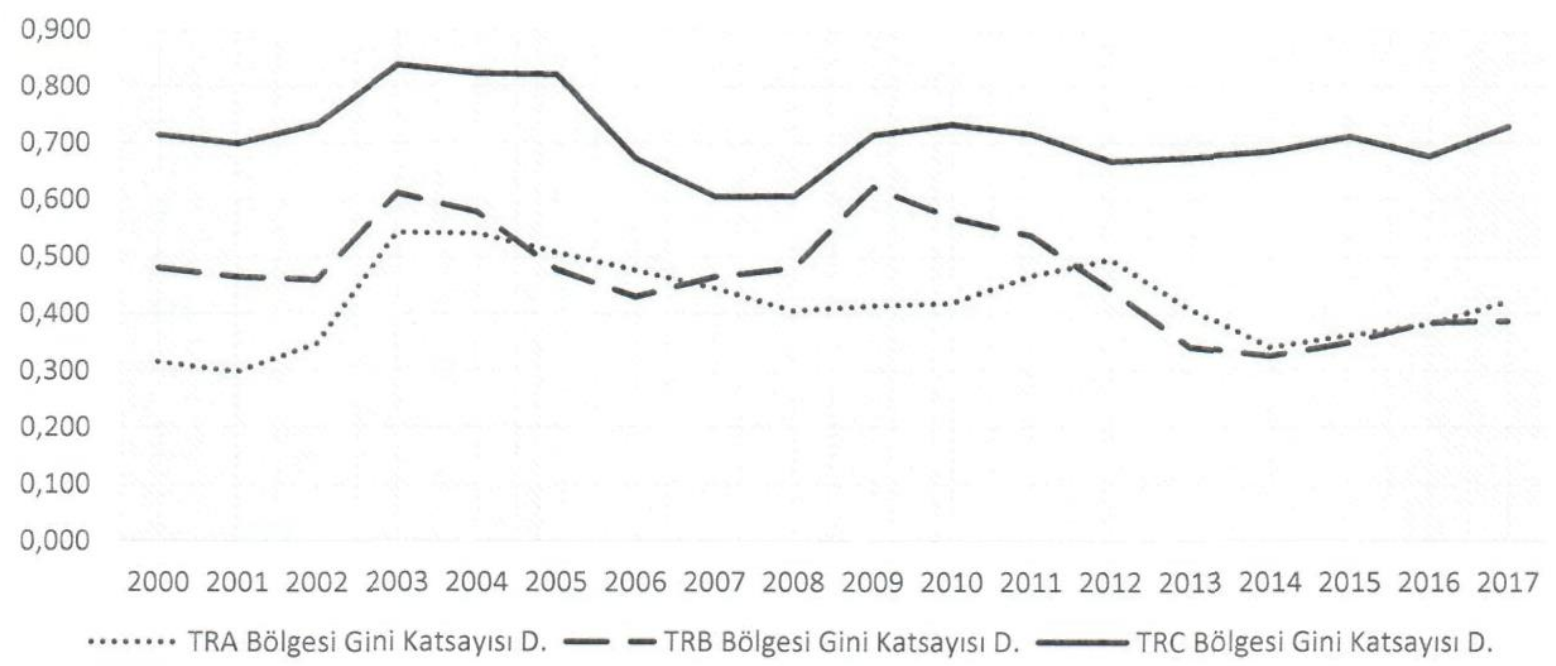

Şekil. 2. TRA, TRB, TRC Bölgelerinde Kamu Tarım Yatırımları Gini Katsayısı Değerlerinin Seyri (2000-2017)

Çalışmada, TRC Bölgesinin Gini Katsayısı değerlerinin, Düzey-1 Bölgeleri olan TRA ve TRB Bölgeleri ile yapılan karşılaştırma bölgesel kalkınma projeleri olan GAP ve DAP Bölgeleri için de yapılmaktadır. İnceleme döneminde GAP ve DAP Bölgesi illerine ait ortalama Gini Katsayı değerleri sırasıyla 0.712 ve 0.442 seviyesinde bulunmaktadır. $\mathrm{Bu}$ durum Gini Katsayı değerinin ortalama değeri açısından bakıldığında GAP Bölgesinde kamu tarım yatırımlarının DAP Bölgesine kıyasla daha eşitsiz dağıldığını göstermektedir.

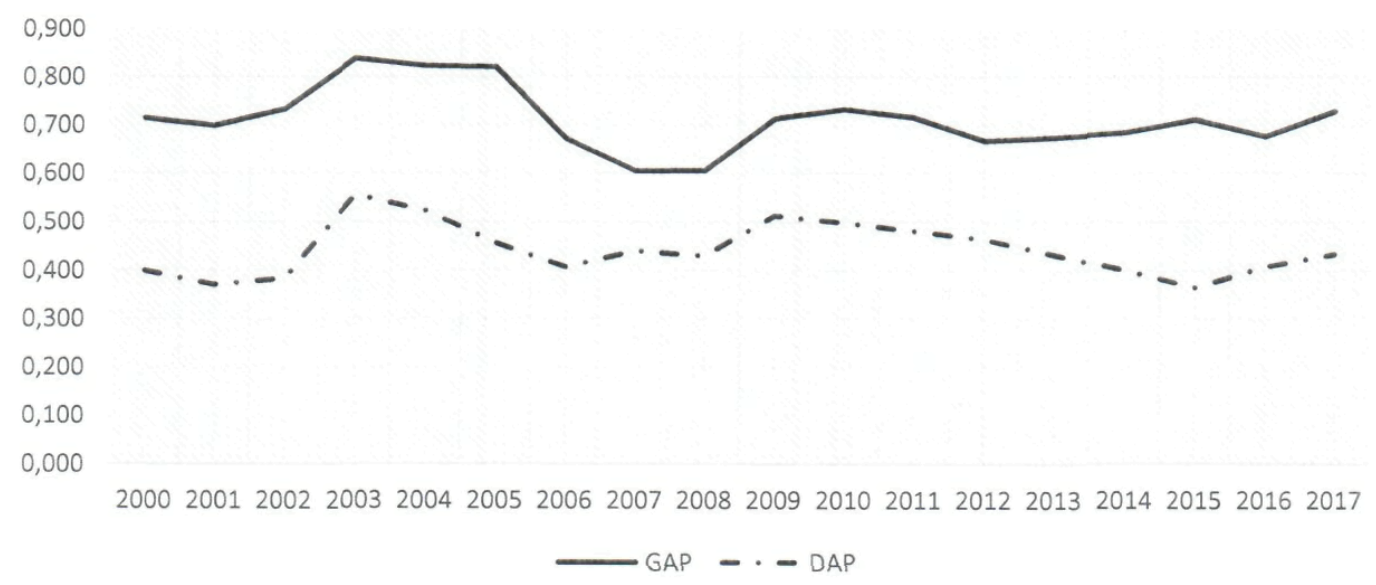

Şekil. 3. GAP ve DAP Bölgelerinde Kamu Tarım Yatırımları Gini Katsayısı Değerlerinin Seyri (2000-2017) 
İnceleme döneminde GAP ve DAP Bölgelerinde Kamu Tarım Yatırımları Gini Katsayısı Değerlerinin Seyri ise Şekil 3'de gösterilmektedir. Şekil 3 incelendiğinde 2000-2017 döneminde GAP Bölgesi için hesaplanan Gini Katsayısı değerlerinin DAP Bölgesi Gini Katsayısı değerlerinden daha yüksek seviyede bulunduğunu ve kamu tarım yatırımlarının GAP Bölgesinde daha eşitsiz dağıldığını göstermektedir.

Yukarıda yapılan analizlerde TRC Bölgesinde kamu tarım yatırımlarının dağılımında eşitsizliğin nasıl bir seyir izlediği görülmekle birlikte eşitsizliğin ne kadarının kamu tarım yatırımlarının TRC
Bölgesinin alt bölgeleri içerisindeki dağılımından ne kadarının ise kamu tarım yatırımlarının bölgeler arası dağılım farklılığından kaynaklandığı anlaşılamamaktadır. Çalışmada eşitsizliğin bu boyutunu da görebilmek amaciyla Lambert and Aronson (1993)'un geliştirdiği yöntem kullanılarak Gini Katsayısı Ayrıştırma Analizi yapılmaktadır. Gini Katsayısı Ayrıştırma Analizi kullanılarak bölge içi ve bölgeler arası eşitsizliğin toplam eşitsizliğe katkısının ortaya çıkarılması amaçlanmaktadır. Çizelge 4'de 2000 ve 2017 yılları için Gini Katsayısı Ayrıştırma Analizinin sonuçları verilmektedir.

Çizelge 4. TRC Bölgesi Gini Ayrıştırma Analizi Sonuçları (2000 ve 2017)

\begin{tabular}{lcccc}
\hline & \multicolumn{2}{c}{$\mathbf{2 0 0 0}$} & \multicolumn{2}{c}{$\mathbf{2 0 1 7}$} \\
\hline & Katsayı & Oran (\%) & Katsayı & Oran (\%) \\
\hline Bölgeler Arası Eşitsizlik & 0.648 & 90,76 & 0.648 & 88,89 \\
Bölgeler İçi Eşitsizlik & 0.066 & 9,24 & 0.081 & 11,11 \\
\hline Toplam & 0.714 & 100,00 & 0.729 & 100,00 \\
\hline
\end{tabular}

Çizelge 4.'de gösterilen Gini Ayrıștırma Analizi sonuçlarına göre, kamu tarım yatırımları için 2000 yılında 0.714 olarak hesaplanan Gini Katsayısı değeri içerisinde bölgeler arası eşitsizliğin payının yüzde 90,76, bölgeler içi eşitsizliğin payının ise yüzde 9,24 olduğu görülmektedir. 2017 y1lı için ise 0.729 olarak hesaplanan Gini Katsayısı değerinin ifade ettiği eşitsizlik içerisinde bölgeler arası ve bölgeler içi eşitsizliği payları ise sırasıyla yüzde 88,89 ve yüzde 11,11 düzeyinde bulunmaktadır. Ulaşılan bu sonuçlar, 2000 yılından 2017 yılına gelindiğinde TRC Bölgesinde bölgeler arası eşitsizliğin azalmaya başladığını, ancak bölge içi eşitsizliğin arttığını göstermektedir.

\section{SONUÇ}

Çalışmada TRC Bölgesinde kamu tarım yatırımlarının 2000-2017 y1lları arasında iller ve alt bölgeler bazında ne kadar eşit/eşitsiz dağıldığının Gini Katsayı kullanılarak incelenmesi amaçlanmaktadır. TRC Bölgesinde kamu tarım yatırımları için Kovaryans yöntemiyle hesaplanan Gini Katsayılarının ortalama değeri 0.712 gibi yüksek bir değer almakta ve bu yüksek Gini Katsayısı değeri kamu tarım yatırımlarının TRC Bölgesinde eşitsiz dağıldığını göstermektedir. İnceleme döneminde kamu tarım yatırımları Gini Katsayısının seyrine bakıldığında ise söz konusu katsayının 2003 yılında 0.838, 2007 yılında ise 0.605 seviyelerinde bulunduğu görülmektedir. Gini Katsayısının aldığı bu değerler, kamu tarım yatırımlarının dağılımının en kötü (en eşitsiz) ve en iyi (en eşit) olduğu yılların sırasıyla 2003 ve 2007 yılları olduğu şeklinde yorumlanmaktadır. TRC
Bölgesinde bulunan iller aynı zamanda Cumhuriyet tarihinin en kapsamlı bölgesel kalkınma projesi olan GAP bünyesinde bulunmaktadır. TRA ve TRB Bölgeleri ve Türkiye'deki diğer önemli bölgesel kalkınma projelerinden birisi olan DAP illeri ile karşılaştırıldığında elde edilen sonuçlar hem ortalamada hem de inceleme dönemi boyunca kamu tarım yatırımlarının en eşitsiz dağıldı̆̆ı bölgenin / bölgesel kalkınma projesinin TRC Bölgesi/ GAP İlleri olduğunu göstermektedir. TRC Bölgesi// GAP İllerinde bölge içi ve bölgeler arası eşitsizliğin toplam eşitsizliğe katkısının ortaya çıkarılması amacıyla yapılan Gini Katsayısı Ayrıştırma Analizi sonuçları ise 2000 yılından 2017 yılına gelindiğinde TRC Bölgesinde bölgeler arası eşitsizliğin azalmaya başladığını, ancak bölge içi eşitsizliğin arttığını göstermektedir.

\section{KAYNAKLAR}

Anonim, 2018a. GAP ve Tarım. T.C. Sanayi ve Teknoloji Bakanlığı GAP Bölge Kalkınma İdaresi Başkanlığı. Şanlıurfa. http://www.gap.gov.tr/tarim-sayfa-15.html.

(Erişim Tarihi:15 Aralık 2018).

Anonim, 2018b. Kamu Yatırımları. Türkiye Cumhuriyeti Cumhurbaşkanlığı Strateji ve Bütçe Başkanlığı. Ankara. http://www2.kalkinma.gov.tr/kamuyat/ilözet.ht ml. (Erişim Tarihi: 5 Ocak 2018).

Barro, R.J., 1990. Government Spending in a Simple Model of Endogenous Growth. Journal of Political Economy, 98 (5): 103-125. 
Brown, M. 1994. Using Gini-Style Indices to Evaluate the Spatial Patterns of health Practitioners; Theoretical Considerations and an Application Based on the Alberta Data. Social Science and Medicine, 38 (9): 1243-1256.

Ceriani, L., Verme, P. 2014. Individual Diversity and the Gini Decomposition, The World Bank Middle East and North Africa Region Poverty Reduction and Economic Management Department Policy Research Working Paper (Online)http://documents.worldbank.org/curate d/en/131591468323697607/pdf/WPS6763.pdf (Erişim Tarihi: 13 Aralık 2018).

Cullis, J., Van Koppen, B., 2007. Applying the Gini Coefficient to Measure Inequality of Water Use in the Olifants River Water Management Area, South Africa. Research Report (Online) http://www.iwmi.cgiar.org/Publications/IWMI_ Research_Reports/PDF/PUB113/RR113.pdf (Erişim Tarihi: 5 Ocak 2018).

Dinler, Z., 2014. Bölgesel İktisat. Ekin Basım Yayın Dağıtım, Bursa, $449 \mathrm{~s}$.

Easypol, 2006. Policy Impacts on Inequality Decomposition of Income Inequality by Subgroups. Analytical Tools Module 52. http://www.fao.org. (Erişim Tarihi: 5 Ocak 2018).

Geyik, P. Ö., Uludağ, A.K., Karabulut, E., Saraçbaş1, O., 2005. Yaşam Sürelerindeki Farklılıkların Gini Katsayısı ile incelenmesi. VIII. Ulusal Biyoistatistik Kongresi Bildirileri, 20-22 Eylül 2005, Bursa, s: 324-332.

Gini, C., 1912. Variabilità e Mutuabilità. Contributo allo Studio delle Distribuzioni e delle Relazioni Statistiche, Studi Economico-Giuridici dell'Universit'a di Cagliari, III, 168 p.

Fidan, H., 2017. Türkiye'de Sayısal Bölünme Düzeylerinin Belirlenmesinde Gini Yaklaşımı. Business and Economics Research Journal, 8 (1): 49-62.

Kaya, E., Şenesen, Ü., 2011. Türkiye'de Gelir Bölüşümü Eşitsizliğine Cinsiyet Ayrımının Katk1s1. Atatürk Üniv. İIBF Derg., 10. Ekonometri ve İstatistik Sempozyumu Özel Say1s1, 25: 181-205.

Lambert P.J., Aronson J.R., 1993. Inequality Decomposition Analysis and the Gini Coefficient Revisited. Economic Journal. 103 (420): 1221-1227.

Lee, W.C. 1996. Analysis of Seasonal Data Using the Lorenz Curve and the Associated Gini Index. International Journal of Epidemiology, 25 (2): 426-434.

Lee, W. C,. 1997. Characterizing Exposure-disease Association in Human Populations Using the
Lorenz Curve and Gini Index. Statistics in Medicine, 16 (7): 729-739.

Lee, S., Lee, S.M., Lee, K., 2017. A Gini Coefficient Based Evaluation on Reliability of Travel Time Forecasting. Journal of King Saud University Engineering Sciences (Online) https://www.sciencedirect.com/journal/journalof-king-saud-university-engineering-sciences (Erişim Tarihi: 10 Ocak 2018).

Lerman, R. I., Yitzhaki, S., 1985. Income Inequality Effects by Income Source: A New Approach and Applications to the United States. The Review of Economics and Statistics, 67 (1): 151-156.

Lucas, R. E. Jr., 1988. On the Mechanics of Economic Development. Journal of Monetary Economics, 22 (1): 3-42.

Öztürk, L., Aktar, İ., 2009. Karadeniz Bölgesi İlerinde Kamu Tarım Yatırımları Dağılımının Gini Katsayısı İle Ölçülmesi. Karadeniz Araştırmaları, 6 (21): 113-122.

Öztürk, L., 2012. Kamu Yatırımları ve Bölgesel Eşitsizlik: Bir Nedensellik Analizi, 1975-2001. Ege Akademik Bakış, 12 (4): 487-495.

Romer, P. M., 1990. Endogenous Technological Change. Journal of Political Economy, 98 (5): 71-102.

Samman, E., 2005. Gini Coefficients for Subsidy Distribution in Agriculture. Human Development Report Office Occasional Paper. (Online)http://hdr.undp.org/sites/default/files/hd r2005_samman_emma_35.pdf (Erişim Tarihi: 10 Ocak 2018).

Tomul, E., 2011. Educational Inequality in Turkey: An Evaluation by Gini Index. Education and Science, 36 (160): 133-143.

Şenses. F., 2017. İktisada (Farklı Bir) Giriş Giriş İktisadı Öğrencileri ve İktisada İlgi Duyanlar İçin Yardımcı Kitap. İletişim Yayınları. İstanbul, $632 \mathrm{~s}$.

$\mathrm{Xu}, \mathrm{K}$., 2003. How Has the Literature on Gini's Index Evolved in the Past 80 Years? Dalhousie University, Economics Working Paper (Online) https://ssrn.com/abstract=423200 (Erişim Tarihi: 10 Ocak 2018).

Yazgan, Ş., 2018. Kamu Yatırımları Dağılımının Gini Katsayısı İle Ölçülmesi: Türkiye Üzerine Bir Uygulama (1999-2017). International Journal of Economics Politics Humanities and Social Sciences, 1 (1): 35-44.

Yazgan, Ş. ve Kadanalı, E., 2018. Kamu Tarım Yatırımlarının Dağılımının Gini Katsayısı ile Ölçülmesi: Kuzeydoğu Anadolu (TRA) Bölgesi İlleri Üzerine Bir İnceleme (1999-2017). Tarım Ekonomisi Derg., 24 (1): 33-42. 